\title{
UK Adolescent School Pupils' Beliefs about Participation in Extra-Curricular Dance
}

\author{
Steven D. Anderson ${ }^{1, *}$, Sandra D. Leyland ${ }^{1}$, Jonathan Ling ${ }^{2}$ \\ ${ }^{1}$ Department of Sport and Exercise, University of Sunderland, Sunderland, United Kingdom \\ ${ }^{2}$ Department of Pharmacy, University of Sunderland, Sunderland, United Kingdom \\ *Corresponding Author: steven.d.anderson@sunderland.ac.uk
}

Copyright $(\subseteq 2013$ Horizon Research Publishing All rights reserved.

\begin{abstract}
Background/Objectives: Dance is part of the National Curriculum for schools in the United Kingdom (UK) and many schools also offer dance as an extra-curricular activity. However, motivation to participate appears to be low. The purpose of this study was to identify the beliefs of UK adolescent school pupils that underpin motivation to participate in extra-curricular dance based on the Theory of Planned Behaviour (TPB) [1]. Method/Design: We employed a semi-qualitative method to elicit salient outcome (instrumental and affective), normative and control beliefs about extra-curricular dance participation. Participants were 28 schoolchildren aged 11-13. Content analysis was used to quantify the beliefs cited based on sample frequency. Results: The most cited three instrumental outcome beliefs were, in rank order, use of time, enjoyment, and impact on ability. Affective outcome beliefs were enjoyment, socialising, and expressing myself. Social referents were family, peers, and (non-dance) teachers. Control beliefs were accessibility, dance competence, and time and commitments. Conclusions: The results presented represent the beliefs of a small sample of schoolchildren regarding their motivation for extra-curricular dance participation. Ultimately these beliefs can be used to aid the development of strategies to enhance motivation for extra-curricular activities such as dance with this age group.
\end{abstract}

Keywords Adolescents, Dance, Motivation, Physical Activity

\section{Introduction}

Extra-curricular physical activity is 'the provision of activities outside of the formal PE curriculum' [2]. In the UK, most schools offer a range of activities outside regular school hours. However, only $41 \%$ of young people in the UK take part in physical activities organised by schools outside of curriculum time [3]. A number of factors underpin the provision of extra-curricular physical activity within any one school, one important consideration is the interplay between what the school is able to provide and what the pupils are willing to participate in [4]. Understanding motivation to participate is an important consideration if the aim is to encourage participation in the activities a school has to offer.

Previous research demonstrates that extra-curricular physical activity is worthwhile as it is a contributing factor for attaining adolescent physical activity guidelines [5,6] and has a significant influence on lifelong participation in physical activity [7]. Participation in extra-curricular physical activity is also beneficial for physical and psychological health, such as maintaining higher health-related fitness and more positive self-perception $[8,9]$. However, participation in physical activities in general appears to be low in adolescence, decreasing from the age of 11 to its lowest by age 16, particularly in girls [3].

One type of extra-curricular physical activity offered by schools is dance. Dance is part of the National Curriculum and shares the health and fitness aims and objectives of PE in the UK [10]. As a lifestyle activity, the popularity of dance continues to grow and the numbers of adults taking part in recreational dance have increased since the mid-1990s [3]. In addition to health benefits, dance promotes individual as well as small group activity, which has been found to help some pupils avoid potentially embarrassing situations that can negatively impact their self-esteem [11].

Although popular with adolescent girls, dance as part of the PE curriculum and as an extra-curricular activity is unpopular with boys $[4,12]$. The need to promote positive attitudes to dance among males is acknowledged by the Arts Council [13], and is supported by empirical research in the UK [14]. Encouraging females to take part in extra-curricular dance is also important given the accelerated decline reported in physical activity throughout adolescence [15]. In order to encourage participation of pupils attending schools offering dance, it is first necessary to understand why there is low participation motivation.

Participation involves a decision to carry out a behavioural action and therefore may be better understood from the perspective of a social cognitive model such as the Theory of Planned Behaviour $[1,16]$. This model explains the decision process that underlies motivation for behaviour. 
The TPB has been utilised extensively to predict a range of behaviours including leisure time physical activity [17]. However, no prior work has applied the TPB specifically to extra-curricular dance participation.

According to the TPB, the strongest predictor of behaviour is a person's intention. Intention is a function of three distinct social cognitive variables: attitude; subjective norm and perceived behavioural control. Attitude is conceptualised as the favourableness of an action and is considered to be a composite of salient outcome beliefs regarding the perceived positive and negative consequences of behavioural enactment. A focus on attitude is important as attitude is consistently found to be the strongest determinant of physical activity motivation [18]. A conceptual distinction is made between two types of outcome beliefs. Instrumental beliefs are beliefs about the "costs and benefits of engaging in the behaviour" [19]. Affective beliefs are beliefs about the "positive or negative feelings derived from the behaviour" [19]. The distinction is supported by findings that the content of outcome beliefs can differ depending on whether questions aim to elicit instrumental or affective beliefs [19-21]. The distinction is relevant in the present study as affective components of attitude are often a stronger determinant of physical activity intention than instrumental ones (see [20,22]). Both instrumental and affective beliefs therefore should be assessed in the context of extra-curricular dance.

Subjective norm is the perception of social pressure and reflects perception of whether a person or group is supportive or opposed to the behaviour. Normative beliefs are the social referents identified as relevant in the context of the target behaviour. For example, teachers may influence pupils' decisions to take part in extra-curricular dance. The third determinant, perceived behavioural control, incorporates the concept of self-efficacy or confidence in ability, and reflects the ease or difficulty of performing an activity when barriers or facilitators arise. Control beliefs are therefore the perceived personal and situational participation barriers and facilitators. For example, the accessibility of the venue or a child's perceived level of dance competence may impact upon their decision to attend extra-curricular dance.

According to the TPB, changes in motivational intention and consequent behaviour will occur if the outcome, normative and control beliefs that support the behaviour are enhanced [1]. Understanding the beliefs that underpin participation motivation may therefore ultimately offer insight into ways of promoting school based extra-curricular dance. The aim of this paper therefore is to identify the salient affective and instrumental outcomes, normative and control beliefs that underpin motivation for participation in extra-curricular dance with UK adolescent school pupils.

\section{Materials and Methods}

\subsection{Design}

A cross-sectional design followed the procedural guidelines of Ajzen [23]. A semi-structured questionnaire was used with a method of rapid elicitation to identify a modal set of salient beliefs about taking part in extra-curricular dance.

\subsection{Participants}

Participants were an opportunity sample of 28 adolescents (aged 11-13) selected from one secondary school in the North East of England. There were 12 males and 16 females (M 12.5 years, SD 0.57).

\subsection{Procedure}

A pilot study was first carried out to check for suitability of the language used with a class of school pupils equivalent in age to the youngest participant in the main study. Participants were presented with eight open questions in the form of a semi-structured questionnaire. Participants were instructed to give as many verbal responses as they could. The researcher wrote down their responses and explained questions if requested. On completion of data collection, all participants were offered the opportunity to ask any questions. This study was approved by the university ethics committee.

\subsection{Measures}

The target behaviour was defined as 'taking part in dance in school as an extra-curricular activity within the next two weeks'. Instrumental and affective outcome beliefs were elicited with a request to list the 'advantages' and 'disadvantages' and the 'things you would like' and 'things you would dislike' respectively. Normative beliefs were elicited by asking for 'people or groups of people' who would 'approve' and 'disapprove' respectively. Control beliefs were elicited by asking for personal or situational circumstances that would 'make it easy' and 'make it hard' to participate. The order in which the questions were presented remained the same throughout as previous research suggests that responses are not influenced by question order [21]. Instrumental outcome beliefs were elicited first followed by affective outcome beliefs, normative beliefs, and finally control beliefs.

\subsection{Data Analysis}

Content analysis was used to identify the most frequently cited words and phrases in response to the eight categories described above. A code frame was then used by two researchers familiar with the TPB, to code the content of all 28 questionnaires. Inter-rater reliability, measured by Cohen's kappa, ranged from .82 to .96 indicating an excellent level of agreement.

\section{Results}


Modal sets are presented in Tables 1 to 8 . The line indicates which belief categories were cited by $20 \%$ or more of the sample. Outcome, normative, and control beliefs were coded and are presented in rank order from the most frequently cited to the least. Due to the small sample size and minimal differences in the categories that emerged, data are not differentiated between boys and girls.

\subsection{Outcome Beliefs}

Responses to open questions about instrumental and affective outcome beliefs are illustrated in Tables 1 to 4 .

Table 1. Modal set of instrumental outcome beliefs for dance as an extra-curricular activity

$\begin{array}{lcc}\text { Belief category } & \text { Sample Frequency } & \begin{array}{c}\text { Sample Frequency } \\ \text { Percentage }(\%)\end{array} \\ \text { Use of time } & 21 & 75.0 \\ \text { Enjoyment } & 18 & 64.2 \\ \text { Impact on ability } & 17 & 60.7 \\ \text { Health and fitness } & 14 & 50.0 \\ \text { A way to socialise } & 14 & 50.0 \\ \text { Embarrassment } & 7 & 25.0 \\ \text { Motivation } & 5 & 17.8 \\ \text { Expressing myself } & 4 & 14.2 \\ \text { Perceived as feminine } & 3 & 10.7 \\ \text { Music } & 0 & - \\ \text { Unclassifiable } & 9 & 32.1 \\ \text { No-one don'tlnow } & 0 & -\end{array}$

Note: the line represents the cut-off point for beliefs included within the modal set.

Table 2. Modal set of affective outcome beliefs for dance as an extra-curricular activity

$\begin{array}{lcc}\text { Belief category } & \text { Sample Frequency } & \begin{array}{c}\text { Sample Frequency } \\ \text { Percentage }(\%)\end{array} \\ \text { Enjoyment } & 18 & 64.2 \\ \text { A way to socialise } & 15 & 53.5 \\ \text { Expressing myself } & 14 & 50.0 \\ \text { Use of time } & 10 & 35.7 \\ \text { Impact on ability } & 10 & 35.7 \\ \text { Embarrassment } & 9 & 32.1 \\ \text { Motivation } & 8 & 28.5 \\ \text { Music } & 6 & 21.4 \\ \text { Perceived as feminine } & 5 & 17.8 \\ \text { Health and fitness } & 4 & 14.2 \\ \text { Unclassifiable } & 6 & 21.4 \\ \text { No-one don'thow } & 1 & 3.5\end{array}$

Enjoyment, a way to socialise, use of time, impact on ability and embarrassment emerged as both instrumental and affective beliefs (see Tables 1 and 2). There were however differences in the number and content of beliefs selected to make up a modal set (see Table 2). Six instrumental outcome beliefs were cited by $20 \%$ or more of the sample in comparison with eight affective outcome beliefs. 'Health and fitness', for example, was cited as an instrumental belief by
$50 \%$ of the sample, however less than $20 \%$ cited this as an affective belief. Similarly, although 'motivation' and 'music' were cited with enough frequency to be selected in the affective modal set, neither were included in the instrumental modal set.

Table 3. Advantages and disadvantages of dance as an extra-curricular activity

\begin{tabular}{|c|c|c|c|c|c|}
\hline \multirow{3}{*}{$\begin{array}{l}\text { Belief } \\
\text { Category }\end{array}$} & \multicolumn{3}{|c|}{ Advantages } & \multicolumn{2}{|c|}{ Disadvantages } \\
\hline & Sample & \multicolumn{2}{|c|}{ Sample } & Sample & Sample \\
\hline & frequency & \multicolumn{2}{|c|}{$\begin{array}{l}\text { frequency } \\
\text { Percentage }(\%)\end{array}$} & frequency & $\begin{array}{l}\text { frequency } \\
\text { percentage }(\%)\end{array}$ \\
\hline \multicolumn{2}{|c|}{ Enjoyment } & 16 & 57.1 & 5 & $17.8=-2$ \\
\hline \multicolumn{2}{|c|}{ Impact on ability } & 14 & 50.0 & 7 & 25.0 \\
\hline \multicolumn{2}{|c|}{ Health and fitness } & 14 & 50.0 & 1 & 3.5 \\
\hline \multicolumn{2}{|c|}{ A way to socialise } & 14 & 50.0 & 2 & 7.1 \\
\hline \multicolumn{2}{|c|}{ Use of time } & 10 & 35.7 & 18 & 64.2 \\
\hline \multicolumn{2}{|c|}{ Expressing myself } & 3 & 10.7 & 1 & 3.5 \\
\hline \multicolumn{2}{|c|}{ Motivation } & 0 & - & 4 & 14.2 \\
\hline \multicolumn{2}{|c|}{ Embarrassment } & 0 & - & 7 & 25.0 \\
\hline \multicolumn{2}{|c|}{ Perceived as feminine } & 0 & - & 3 & 10.7 \\
\hline \multicolumn{2}{|c|}{ Music } & 0 & - & 0 & - \\
\hline \multicolumn{2}{|c|}{ Unclassifiable } & 1 & 3.5 & 8 & 28.5 \\
\hline \multicolumn{2}{|c|}{ No-one don't lnow } & 0 & - & 0 & - \\
\hline
\end{tabular}

Table 4. Likes and dislikes of dance as an extra-curricular activity

\begin{tabular}{lllll}
\multicolumn{3}{c}{ Likes } & \multicolumn{2}{c}{ Dislikes } \\
$\begin{array}{l}\text { Belief } \\
\text { Category }\end{array} \quad \begin{array}{c}\text { Sample } \\
\text { frequency }\end{array}$ & $\begin{array}{l}\text { Sample } \\
\text { frequency } \\
\text { Percentage (\%) }\end{array}$ & $\begin{array}{l}\text { Sample } \\
\text { frequency }\end{array}$ & $\begin{array}{l}\text { Sample } \\
\text { frequency } \\
\text { percentage (\%) }\end{array}$ \\
Expressing myself & 14 & 50.0 & 5 & 17.8 \\
A way to socialise & 13 & 46.4 & 0 & - \\
Enjoyment & 11 & 39.2 & 11 & 39.2 \\
Music & 6 & 21.4 & 0 & - \\
Impact on ability & 4 & 12.2 & 0 & - \\
Motivation & 4 & 12.2 & 5 & 17.8 \\
Health and fitness & 3 & 10.7 & 7 & 25.0 \\
Use of time & 1 & 3.5 & 10 & 35.7 \\
Embarrassment & 0 & - & 9 & 32.1 \\
Perceived as feminine & 0 & - & 5 & 17.8 \\
Unclassifiable & 1 & 3.5 & 5 & 17.8 \\
No-one don'tlnow & 1 & 3.5 & 0 & -
\end{tabular}

The most frequently cited of the nine disadvantages was 'waste of time' (see Table 3), whereas the most frequently cited of the eight dislikes was 'lack of enjoyment' (see Table 4). The category 'music' emerged within the top four outcome beliefs in response to 'likes', but was not cited as an 'advantage'. Differentiation between the two types of outcome belief is therefore partially supported.

Table 5. Modal set of normative beliefs for dance as an extra-curricular activity

\begin{tabular}{lcc} 
Belief category & Sample Frequency & $\begin{array}{c}\text { Sample Frequency } \\
\text { Percentage }(\%)\end{array}$ \\
Family & 28 & 100 \\
Peers & 24 & 85.7 \\
Teachers & 15 & 53.5 \\
Danceteachers & 12 & 42.8 \\
\hline Unclassifiable & 2 & 7.1 \\
No-one don'tlnow & 1 & 3.5
\end{tabular}


Table 6. Referents who approve and disapprove of dance as an extra-curricular activity

\begin{tabular}{|c|c|c|c|c|}
\hline \multirow[b]{2}{*}{$\begin{array}{l}\text { Belief } \\
\text { Category }\end{array}$} & \multicolumn{2}{|c|}{ Approve } & \multicolumn{2}{|c|}{ Disapprove } \\
\hline & $\begin{array}{l}\text { Sample } \\
\text { frequency }\end{array}$ & $\begin{array}{l}\text { Sample } \\
\text { frequency } \\
\text { Percentage }(\%)\end{array}$ & $\begin{array}{l}\text { Sample } \\
\text { frequency }\end{array}$ & $\begin{array}{l}\text { Sample } \\
\text { frequency } \\
\text { percentage }(\%)\end{array}$ \\
\hline Family & 21 & 75.0 & 17 & 60.7 \\
\hline Peers & 19 & 67.8 & 23 & 82.1 \\
\hline Teachers & 15 & 53.5 & 0 & - \\
\hline Dance teachers & 10 & 35.7 & 3 & 10.7 \\
\hline Unclassifiable & 1 & 3.5 & 0 & - \\
\hline $\begin{array}{l}\text { No-onedon't } \\
\text { know }\end{array}$ & 2 & 7.1 & 0 & - \\
\hline
\end{tabular}

\subsection{Normative Beliefs}

Four social referents made up the modal normative belief set: 'family'; 'peers'; 'teachers' and 'dance teachers' (see Table 5). Family and peers were cited with the most frequency with all participants citing 'family'. Although $75 \%$ believed that some family members would approve, nearly $70 \%$ thought that some family members would disapprove. Surprisingly, three participants thought that the dance teacher would disapprove (see Table 6).

Table 7. Modal set of control beliefs for dance as an extra-curricular activity within school

$\begin{array}{llc}\text { Belief category } & \text { Sample Frequency } & \begin{array}{c}\text { Sample Frequency } \\ \text { Percentage }(\%)\end{array} \\ \text { Accessibility } & 22 & 78.5 \\ \text { Dance competence } & 15 & 53.5 \\ \text { Time and commitments } & 13 & 46.4 \\ \text { Social support } & 11 & 39.2 \\ \text { Cost } & 9 & 32.1 \\ \text { Motivation } & 9 & 32.1 \\ \text { Type of music } & 4 & 14.2 \\ \text { Type of clothes } & 3 & 10.7 \\ \text { The other people there } & 3 & 10.7 \\ \text { Injury illness } & 2 & 7.1 \\ \text { Liking the Teacher } & 2 & 7.1 \\ \text { Venue } & 2 & 7.1 \\ \text { Type of dance } & 1 & 3.5 \\ \text { Unclassifiable } & 4 & 14.2 \\ \text { No-one don'tlnow } & 0 & -\end{array}$

Table 8. Things that make it easy and difficult to take part in dance as an extra-curricular activity

$\begin{array}{lllll}\begin{array}{l}\text { Belief } \\ \text { Casy }\end{array} & \begin{array}{c}\text { Sample } \\ \text { Category }\end{array} & \begin{array}{l}\text { Sample } \\ \text { frequency }\end{array} & \begin{array}{l}\text { Difficult } \\ \text { frequency } \\ \text { Sample }\end{array} & \begin{array}{l}\text { Sample } \\ \text { frequency } \\ \text { frequency } \\ \text { percentage (\%) }\end{array} \\ \text { Accessibility } & 16 & 57.1 & 16 & 57.1 \\ \text { Dance competence } & 12 & 42.8 & 8 & 28.5 \\ \text { Social support } & 9 & 32.1 & 4 & 14.2 \\ \text { Motivation } & 6 & 21.4 & 3 & 10.7 \\ \text { Time and commitments } & 3 & 10.7 & 12 & 42.8 \\ \text { Cost } & 2 & 7.1 & 7 & 25.0 \\ \text { Liking the teacher } & 2 & 7.1 & 1 & 3.5 \\ \text { Type of clothes } & 1 & 3.5 & 2 & 7.1 \\ \text { Type of music } & 1 & 3.5 & 3 & 10.7 \\ \text { The other people there } & 0 & - & 3 & 10.7 \\ \text { Type of dance } & 0 & - & 1 & 3.5 \\ \text { Injury illness } & 0 & - & 2 & 7.1 \\ \text { Venue } & 0 & - & 2 & 7.1 \\ \text { Unclassifiable } & 2 & 7.1 & 3 & 10.7 \\ \text { No-one don'tlnow } & 0 & - & 0 & -\end{array}$

\subsection{Control Beliefs}

There were 15 control beliefs, six of which were cited by $20 \%$ or more of the sample (see Table 7). 'Accessibility' was the most frequently cited control belief suggesting that location was a primary factor in deciding whether or not to participate. More than $50 \%$ cited 'dance competence' as a potential barrier/facilitator suggesting that dance self-efficacy is another key consideration. 'Time and commitments' was the third most frequently cited control belief. Factors related to the specific dance form such as the 'type of music', 'type of clothing', 'the venue', 'other people there' and 'whether or not the teacher was liked' were mentioned with the lowest frequency.

\section{Discussion}

The aim of this study was to identify the beliefs that underpin the determinants of intention to participate in extra-curricular dance in accordance with the TPB [1], with a group of children who attended a secondary school.

\subsection{Outcome Beliefs}

Enjoyment was the most frequently mentioned advantage and ranked third as something that would be liked about extra-curricular dance. Lack of enjoyment was also cited most frequently as something that would be disliked or hated. Extra-curricular dance participation is therefore likely to increase when pupils' express enjoyment for taking part. This finding reflects previous research which has found that young people regularly report enjoyment or fun as the most important factor impacting on their participation [24].

More than $20 \%$ of the sample also indicated that the biggest disadvantage to taking part in extra-curricular dance was missing out on other free time hobbies and activities. This was not unexpected as young people are known to exhibit a range of leisure time behaviours [25]. Therefore, efforts to engage adolescents in extra-curricular dance may be enhanced by adopting strategies that make dance more enjoyable, as well as offering them at times that do not compete with other more preferred hobbies and activities.

Evidence is available in support of the individual assessment of instrumental and affective beliefs [26]. Despite acknowledging some overlap between the modal sets of instrumental and affective beliefs, marked differences have been found in the beliefs that emerge within the modal set [26]. Our results support the suggestion that eliciting two types of outcome beliefs - instrumental beliefs with a request to list the 'advantages' and 'disadvantages' and affective beliefs with a request to list the 'things you would like' and 'things you would dislike', can result in differences in content and number of beliefs. This was evidenced by the finding that with the exception of enjoyment, the top three instrumental and affective beliefs differed in content. 


\subsection{Normative Beliefs}

TPB research often reports on the role of normative beliefs as offering the least to an individual's intention. However, in young people, social factors appear to have more of an influence on motivation [27]. 'Family' was the most frequently cited normative referent, followed closely by 'peers' and then 'teachers'. This supports previous research [28] which suggests that adolescents consider the approval or disapproval of individuals with whom they have close contact when deciding whether or not to engage in a physical activity.

'Teachers' and 'dancers' were also cited by more than $20 \%$ of the sample. In the context of extra-curricular dance, teachers (both dance and non-dance specialists) have a salient role in the development of subjective norms that underpin motivation for extra-curricular dance participation.

\subsection{Barriers and Facilitators}

The control belief findings of this study are supported in a recent study into the prevalence of barriers for physical activity in Portuguese adolescents [29]. 'Accessibility' was the most cited control belief. A school based location for dance, for some, was perceived as a facilitator of participation while for others, this acted as a barrier as they were dependent on family members for after school pick-up and transport home. The implication is that consideration of access and timing of extra-curricular activity (i.e. school lunch breaks or before or after school) could be a useful means of improving participation. 'Time and commitments' was the third most frequently cited control belief, reflecting previous research that a 'lack of time' is often found to be a main reason for non-participation in physical activity [29].

'Dance competence' was cited as both a perceived facilitator and a barrier to participation suggesting that perception of ability is an important motivational influence. To add to the outcome beliefs of this study, perceived competence has been found to be related to perceptions of enjoyment during PE lessons [30]. This emphasizes that extra-curricular participation may be the result of appropriate challenge set during PE or extra-curricular lessons. 'Social support' was the most frequently cited facilitator with approximately one third of pupils describing how having someone to go with or encourage them was an important factor in their decision to participate. The importance of social support in predicting future activity levels in middle school children has been discussed in recent work on physical activity [31].

Overall, the results suggest that the most salient outcome, normative and control beliefs in the context of extra-curricular dance are whether it is an enjoyable way to socialise, that family members have the strongest normative influence, and that physical limitations regarding location obstruct participation, respectively. These beliefs are the most likely to impact on pupils' choices to take part in extra-curricular dance. This study therefore offers insight into pupils' thoughts on extra-curricular dance which can later be used to promote dance as a physical activity. These beliefs are, in the main, consistent with previous findings in the domain of physical activity research [32]. However, any claims regarding the use of these beliefs to promote extra-curricular dance would need to be tested.

\subsection{Limitations and Recommendations for Future Research}

We used a method of rapid elicitation similar to that used in a study of beliefs about walking [20]. One problem with this method is that participants typically cite only one or two beliefs [21]. It is possible that the method used in the present study restricted the number of beliefs cited by any one individual. However, we do not believe this was the case as most participants cited several beliefs. Further research utilising a more qualitative interview style may provide greater clarity.

The beliefs presented in this study were based on sample frequency. Previous research by Sutton [21] has demonstrated that the number of beliefs can differ depending on whether sample frequency or belief frequency is used to aid the decision regarding the number of beliefs selected as modal. Modal sets based on sample frequency are typically smaller than those based on belief frequency. Furthermore, using a cut-off point of $20 \%$ sample frequency results in exclusion of beliefs that are salient for individuals but less salient for the group as a whole. The implication for doing so is that the results are more generalised and may not account for the beliefs of all participants. The methods used to select the modal beliefs presented in this study should be considered in further research.

The study presented here is descriptive in nature. Further research is needed to develop quantitative measures based on the beliefs presented, in order to establish validity and reliability as predictors of motivation as proposed in the TPB. Further research is also necessary to establish if generalisation beyond the target behaviour presented here to other types of extra-curricular physical activity and curriculum based physical education can be made.

\section{Conclusion}

The present research provides information regarding beliefs that underpin adolescents' motivation for extra-curricular dance. The results of this study could be used to inform the design of larger scale quantitative studies and interventions based on the TPB and aimed at enhancing extra-curricular dance participation. As attitude is often reported to be the strongest predictor of intention [18], changes in negative attitude may result from targeting the most salient beliefs established in this study [33]. In addition, the beliefs also have wider applicability to other extra-curricular activities, aiding and enhancing our understanding of the reasons that influence adolescents' 
decisions to engage in activities that fall outside of the curriculum.

\section{Acknowledgements}

We thank the staff and pupils of the participating school for taking part in this study.

\section{REFERENCES}

[1] I. Ajzen. The Theory of Planned Behavior, Organizational Behavior and Human Decision Processes, Vol.50, 179-211, 1991.

[2] D. Penny, and J. Harris. Extra-curricular physical education: More of the same for the more able." Sport, Education and Society Vol.2 No.1, 44-54, 1997.

[3] Sport England. Young People and Sport in England National Survey 2002. Report no SE/2220/P/02/03, London: Sport England. 2003.

[4] A. Smith, M. Thurston, K. Green, and K. Lamb. Young people's participation in extra-curricular physical education: A study of 15-16 year olds in North-West England and North-East Wales, European Physical Education Review, Vol.13, No.3, 339-368, 2007.

[5] L. Gracia-Marco, C. Tomàs, G. Vicente-Rodríguez, D. Jiménez-Pavon, J. P. Rey-López, F. B. Ortega, R. Lanza-Saiz, and L. A. Moreno. Extra-curricular participation in sports and socio-demographic factors in Spanish adolescents: The AVENA study, Journal of Sports Sciences, Vol.28 No.13, 1383-1389, 2010.

[6] P. Silva, M. Sousa, L. Aires, A. Seabra, J. Ribeiro, G. Welk, and J. Mota. Physical activity patterns in Portuguese adolescents: The contribution of extracurricular sports, European Physical Education Review, Vol.16 No.2, 171-181, 2010.

[7] S. Fairclough, G. Stratton, and G. Baldwin. The contribution of secondary school physical education to lifetime physical activity, European Physical Education Review, Vol.8 No.1, 69-84, 2002.

[8] M. Bronikowski, and M. Bronikowska. Will they stay fit and healthy? A three-year follow-up evaluation of a physical activity and health intervention in Polish youth, Scandinavian Journal of Public Health, Vol.39, 704-713, 2011.

[9] A. J. Daley. Extra-curricular physical activities and physical self-perceptions in British 14-15 year old males and female adolescents, European Physical Education Review, Vol.8 No.1, 37-49, 2002.

[10] Department for Education. Physical Education in the National Curriculum. Report, London: UK, 1995.

[11] L. D. Wiersma, and C. P. Sherman. The responsible use of youth fitness testing to enhance student motivation, enjoyment, and performance, Measurement in Physical Education and Exercise Science, Vol.12, No.3, 167-183, 2008.
[12] A. Smith, M. Thurston, K. Lamb, and K. Green. Young people's participation in national curriculum physical education: A study of 15-16 year olds in North-West England and North-East Wales, European Physical Education Review, Vol.13, No.2, 165-194, 2007.

[13] Arts Council of England (ACE). Consultative Green Paper for Education and Training in the English Arts Funding System. Report, London: ACE, 1996.

[14] P. Sanderson. The arts, social inclusion and social class: the case of dance, British Educational Research Journal, Vol.34 No.4, 467-490, 2008.

[15] Y. S. Sue, M. D. Kimm, N. W. Glynn, A. M. Kriska, B. A. Barton, S. S. Kronsberg, S. R. Daniels, P. B. Crawford, Z. I. Sabry, and K. Liu. Decline in physical activity in black girls and white girls during adolescence, The New England Journal of Medicine, Vol.347 No.10, 709-715, 2002.

[16] I. Ajzen. From intentions to actions: A theory of planned behavior, 1985. In J. Kuhl, \& J. Beckmann. eds. Action-control: From cognition to behavior. Heidelberg: Springer, pp.11-39.

[17] M. S. Hagger, N. L. D. Chatzisarantis, and S. J. H. Biddle. A meta-analytic review of the theories of reasoned action and planned behaviour in physical activity: Predictive validity and contribution of additional variables, Journal of Sport \& Exercise Psychology, Vol.24, 3-32, 2002.

[18] R. E. Rhodes, and C. R. Nigg. Advancing physical activity theory: A review and future directions, Exercise and Sport Science Reviews, Vol.39 No.3, 113-119, 2011.

[19] I. Ajzen, and B. L. Driver. Prediction of leisure participation from behavioral, normative, and control beliefs: An application of the theory of planned behavior, Leisure Science, Vol.13, 185-204, 1991.

[20] C. D. Darker, D. P. French, S. Longdon, K. Morris, and F. F. Eves. Are beliefs elicited biased by question order? A theory of planned behaviour elicitation study about walking in the UK general population, British Journal of Health Psychology, Vol.12 No.1, 93-110, 2007.

[21] S. Sutton, D. P. French, S. J. Hennings, J. Mitchel, N. J. Wareham, and A. L. Kinmonth. Eliciting salient beliefs in research on the theory of planned bahaviour: The effect of question wording, Current Psychology, Vol.22 No.3, 234-251, 2003.

[22] R. Lowe, F. Eves, and D. Carroll. The influence of affective and instrumental beliefs on exercise intentions and behaviour: A longitudinal analysis, Journal of Applied Social Psychology, Vol.32 No.6, 1241-1252, 2002.

[23] I. Ajzen. Constructing a TPB questionnaire: Conceptual and methodological considerations. Accessed March 12. http://www-unix.oit.umass.edu/ aizen:

[24] M. E. Ewing, and V. Seedfeldt. Patterns of sport participation and attrition in American agency-sponsored sports, 1996. In Weinberg, R.S. and Gould, D. 2010. Foundations of Sport and Exercise Psychology. Human Kinetics.

[25] W-D. Brettschneider, and R. Naul. Report: Study on young peoples' lifestyles and sedentariness and the role of sport in the context of education and as a means of restoring the balance, Germany, University of Paderborn. 
[26] D. P. French, S. Sutton, S. J. Hennings, J. Mitchell, N. J. Wareham, S. Griffin, W. Hardeman, and L. Kinmonth. The importance of affective beliefs and attitudes in the theory of planned behavior: Predicting intention to increase physical activity, Journal of Applied Social Psychology, Vol.35, No.9, 1824-1848, 2005.

[27] M. O. M. van de Ven, R. C. M. E. Engels, R. Otten, R. J. J. M. van den Eijnden. A longitudinal test of the theory of planned behavior predicting smoking onset among asthmatic and non-asthmatic adolescents, Journal of Behavioural Medicine, Vol.30, 435-445, 2007.

[28] M. Eddosary, A. Taylor, and P. Freeman. Eliciting the salient beliefs of physical activity for Saudi young people, International Journal of Developmental Sport Management, Vol.1 No.1, 2011.

[29] H. Gomes, D. Pinto, S. Sequeira, L. Santos, A. Marques, and F. Carreiro da Costa. Prevalence of barriers for physical activity in Portuguese adolescents, British Journal of Sports
Medicine, Vol.45, No.15: A19, 2011.

[30] S. Fairclough. Physical activity, perceived competence and enjoyment during secondary school physical education, The European Journal of Physical Education, Vol.8, No.1, 5-18, 2003.

[31] J. J. Martin, N. McCaughtry, S. Flory, A. Murphy, and K. Wisdom. Using social cognitive theory to predict physical activity and fitness in underserved middle school children, Research Quarterly for Exercise and Sport, Vol.82 No.2, 247-255, 2011.

[32] D. S. Downs, and H. A. Hausenblas. Elicitation studies and the theory of planned behaviour: A systematic review of exercise beliefs, Psychology of Sport and Exercise, Vol.6, No.1, 1-31, 2005.

[33] S. Silverman, and P. R. Subramanian. Student attitude toward physical education and physical activity: A review of measurement issues and outcomes, Journal of Teaching in Physical Education, Vol.19, 97-125, 1999. 